\title{
Predictive Control for MPPT in a Single-Stage Photovoltaic System
}

\author{
Carlos Muñoz ${ }^{1}$, Marco Rivera ${ }^{1}$, Ariel Villalón ${ }^{1}$, José Riveros ${ }^{1}$, Javier Muñoz ${ }^{1}$ and Patrick Wheeler ${ }^{2}$ \\ ${ }^{1}$ Faculty of Engineering, Universidad de Talca, Curico, Chile \\ carlosmunoz@utalca.cl; marcoriv@utalca.cl; avillalon@utalca.cl; jriveros@utalca.cl; jamunoz@utalca.cl \\ ${ }^{2}$ Faculty of Engineering, The University of Nottingham, UK \\ Pat.Wheeler@nottingham.ac.uk
}

\begin{abstract}
Predictive control has risen as a plausible option in the control of power converters for photovoltaic utilisation. In this work, a predictive control scheme is proposed to obtain the maximum power point in a photovoltaic array coupled directly to a grid-connected DC/AC power converter. The architecture considered avoids the use of the DC/DC stage, reducing the losses related to the inclusion of the boost stage. The introduced control strategy is proved by simulations in Matlab\&Simulink, demonstrating flexibility to include the non-linear behaviour of the system and satisfying performance in terms of DC voltage and AC current control.
\end{abstract}

Index Terms-Predictive Control, Single-Stage, MPPT, 2-level VSI, Grid-connected

\section{INTRODUCTION}

T here is an increasing interest on the use of renewable energy mainly based on the decrease in the cost of solar photovoltaic (PV) modules and on the decrease of the cost of power converters. These drivers are based on the need of clean, reliable and efficient energy. All these factors have contributed to a wider spread of these technologies.

All of this has led to an increasing use of the available solar irradiance for electricity generation [1]. This is the case of Chile, where one of the highest solar potential of the world can be found, which allows having high capacity factors that make investments more profitable, both on a big scale or at a low scale, i.e. distributed generation which is connected to medium to low voltage networks.

$\mathrm{PV}$ distributed generators require the use of DC/AC power converters to be connected to electrical grids and in returns, to be able to inject power into them [2]. For these applications, power converters commonly use a cascaded DC/DC stage with a DC/AC. The DC/DC stage consists in boost converters that are in charge of stabilising the DC voltage that comes from the solar generator and executes the MPPT [3]. On-grid power converters are also available to control the PV systems but without the use of the DC/DC stage. These architectures are also called single-stage [4]. Nevertheless, this sort of nonDC/DC stage power converters have less development in the industry, though one of its advantages is the higher global efficiency for the power conversion process because of the reduction, mainly, of the commutation losses associated to the inclusion of the DC/DC stage or boost converter [5]. As single-stage do not possess the DC voltage boost capability, they require higher DC voltage in order to provide voltage/var compensation [6]. When there are disturbances from the environment over the PV system, for instance, fast irradiance variation, and disturbances such as fast variations in the load, among others, the two-stage converters are able to absorb those disturbances, in order to have power losses that are not significant. Having a single-stage MPPT VSI eliminates the boost converter losses that are typically of $2.5 \%$, if single and two-stage systems are compared, the single-stage converter has a total power loss smaller than the loss of the two-stage system, with values of $4.34 \%$ and $4.5 \%$, respectively [5].

On the other hand, as microprocessors have had large development, predictive control of power converters and electrical drives have become feasible to be applied. There are several different approaches to develop a controller for power electronics using predictive control. A common feature, which is shared by all of these approaches is that all of them use a model of the system for computing predictions of the future behaviour for the relevant and controlled variables. Later, a cost function is used to choose the proper actuation for the coming period [7].

Implementations of a predictive control technique on PV systems without using DC/DC blocks, e.g. using a single-stage converter architecture, are highly scarce and hard to find in related literature, though it is a feasible and interesting technology to be applied. For instance, in [8] a three-phase singlestage grid-connected photovoltaic system is controlled using a linear PI classic strategy with cross-coupling compensation, and in [9], the authors use a similar PI control for a singlestage 3-level NPC inverter used in an on-grid PV system. In [6], the single-stage grid-connected PV system is controlled using a PI control and the DC voltage with a voltage-oriented control.

In this work a three-phase single-stage 2-level voltage source inverter (VSI) fed directly by an on-grid PV system is developed. In the first part, the topology and the model of the system are described. Then, the predictive control strategy for PV energy injection is obtained and explained and simulation results are discussed. Finally, the conclusions are presented. 


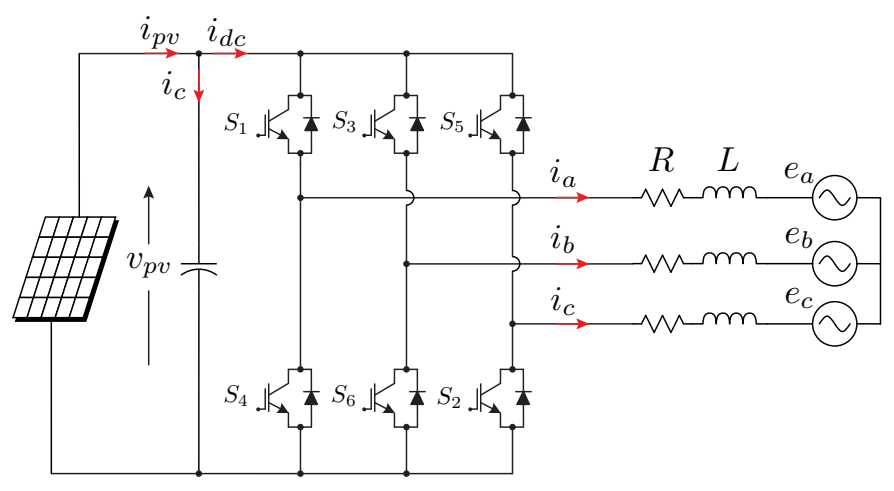

Fig. 1: Voltage source inverter (VSI) connected to an on-grid photovoltaic system

\section{SYSTEM DESCRIPTION}

The system shown in Fig. 1 is composed of a 2-level VSI, with a series-connected solar panels array in parallel with a capacitor in the DC link. The inverter output is connected to the grid. The aim of this work is to implant the produced power via PV panels within the network implementing an MPPT algorithm without the use of DC/DC power converters. Its components are described in the following subsections.

\section{A. Voltage source inverter}

The device in charge of inverting the voltage has three legs, each one with two power switches (Fig.1). These switches can operate independently with the restriction that the IGBTs of a same branch have to work complementarily (one in $\mathrm{ON}$ mode, state 1 , and the other in OFF mode, state 0 ) to not generate destructive overcurrents. Considering this, the valid commutation states are only 8 possible combinations. The valid commutation states can be found in Table I. The voltage at the output of the converter with respect to the negative voltage of the DC link can be declared like the switches states $S_{1}, S_{3}, S_{5}$ and the DC voltage $v_{d c}$ (equivalent to $v_{p v}$ ), as follows:

$$
\boldsymbol{v}=\left[\begin{array}{l}
S_{1} \\
S_{3} \\
S_{5}
\end{array}\right] v_{d c}
$$

The resulting line voltages are summarised in Table II, where also the obtained $i_{d c}$ current is included,

$$
i_{d c}=\left[\begin{array}{lll}
S_{1} & S_{3} & S_{5}
\end{array}\right] \boldsymbol{i}
$$

where $i$ is the vector of the AC line currents; whereas $e_{a}, e_{b}$ and $e_{c}$ are the phase-voltages of the grid (see Fig. 1).

\section{B. Solar photovoltaic system}

The photovoltaic system connected to the DC link of the inverter from Fig. 1 is an array of series or parallel-connected solar cells. In Fig. 2 the electrical representation of a solar cell is shown. The current source represents the delivered energy. The diode is linked to the semiconductor's characteristics of the cell, which allows the electrons to flow in open circuit; $R_{s}$ represents the impurities, connections and welding of the

\begin{tabular}{c|cccccc}
\multicolumn{7}{c}{ TABLE I: VSI valid states } \\
States & $S_{1}$ & $S_{2}$ & $S_{3}$ & $S_{4}$ & $S_{5}$ & $S_{6}$ \\
\hline \hline 1 & 1 & 1 & 0 & 0 & 0 & 1 \\
2 & 1 & 1 & 1 & 0 & 0 & 0 \\
3 & 0 & 1 & 1 & 1 & 0 & 0 \\
4 & 0 & 0 & 1 & 1 & 1 & 0 \\
5 & 0 & 0 & 0 & 1 & 1 & 1 \\
6 & 1 & 0 & 0 & 0 & 1 & 1 \\
7 & 1 & 0 & 1 & 0 & 1 & 0 \\
8 & 0 & 1 & 0 & 1 & 0 & 1 \\
\hline \hline
\end{tabular}

TABLE II: VSI output of currents and voltages

\begin{tabular}{c|cccc} 
States & $V_{a b}$ & $V_{b c}$ & $V_{c a}$ & $i_{d c}$ \\
\hline \hline 1 & $v_{p v}$ & 0 & $-v_{p v}$ & $i_{a}$ \\
2 & 0 & $v_{p v}$ & $-v_{p v}$ & $i_{a}+i_{b}$ \\
3 & $-v_{p v}$ & $v_{p v}$ & 0 & $i_{b}$ \\
4 & $-v_{p v}$ & 0 & $v_{p v}$ & $i_{b}+i_{c}$ \\
5 & 0 & $-v_{p v}$ & $v_{p v}$ & $i_{c}$ \\
6 & $v_{p v}$ & $-v_{p v}$ & 0 & $i_{a}+i_{c}$ \\
7 & 0 & 0 & 0 & 0 \\
8 & 0 & 0 & 0 & 0 \\
\hline \hline
\end{tabular}

system; and finally, $R_{p}$ models the leakage current. Usually, $R_{p}$ has a exceptionally high value when compared to $R_{s}$.

Applying the Kirchhoff's current law (KCL) in the node that contains the diode and the Kirchhoff's voltage law (KVL) in the output of the equivalent circuit (Fig. 2), the following is obtained,

$$
\begin{gathered}
i_{p h}-i_{D}-\frac{v_{D}}{R_{p}}-i_{p v}=0 \\
v_{D}=v_{p v}+i_{p v} R_{s}
\end{gathered}
$$

The behaviour of the diode is described by [10]:

$$
\begin{gathered}
i_{D}=i_{0}\left(e^{\frac{v_{D} q}{k A T_{c}}}-1\right) \\
i_{0}=i_{r s}\left[\left(\frac{T_{c}}{T_{\text {ref }}}\right)^{3} e^{\frac{q E g}{A k}\left(\frac{1}{T_{r e f}}-\frac{1}{T_{c}}\right)}\right] \\
i_{r s}=i_{s c \text { ref }}\left[e^{\frac{q V_{o c}}{k A T}}-1\right]
\end{gathered}
$$

The behaviour of the current source of the PV component is given by $\left(i_{s c ~ r e f}\right.$, short-circuit current at $\left.25\left[{ }^{\circ} \mathrm{C}\right]\right)$ :

$$
i_{p h}=\left[i_{s c \text { ref }}+K_{i}\left(T_{c}-T_{\text {ref }}\right)\right] \frac{g_{h}}{1000}
$$

Taking into account that it is possible to make several solar cells arrays (series and parallel), it is found that $R_{p}>>R_{s}$ and combining the equations (7) and (8), the following expression that defines solar cell current is obtained:

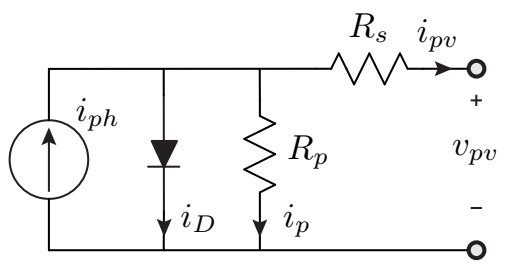

Fig. 2: Solar cell equivalent circuit 

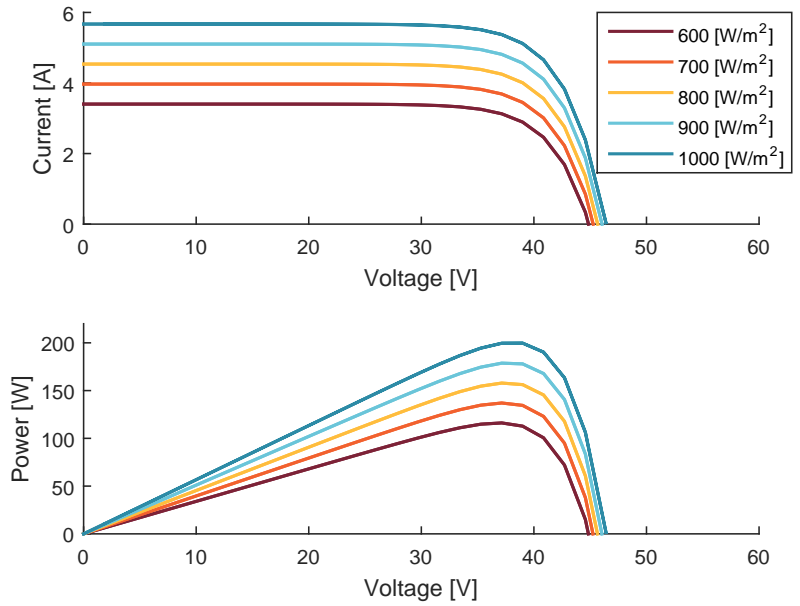

Fig. 3: Curves of current and power when the solar irradiance changes @ $25\left[{ }^{\circ} \mathrm{C}\right]$
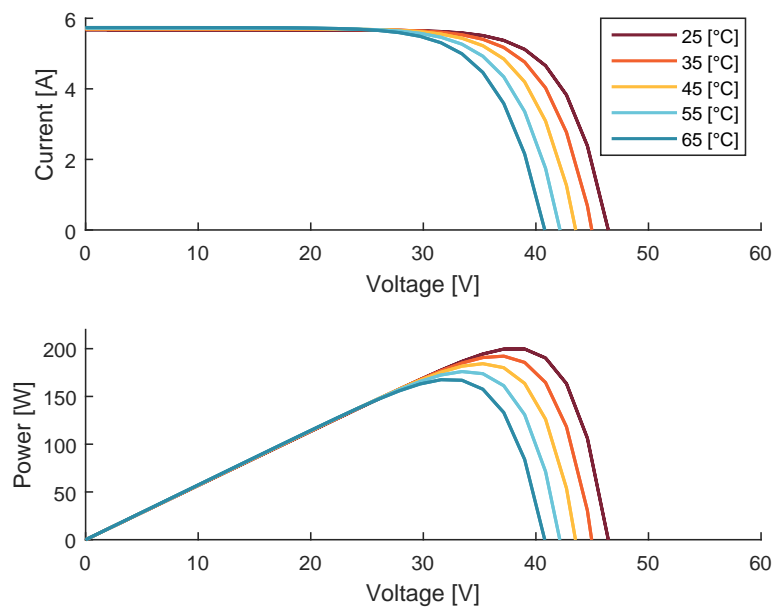

Fig. 4: Curves of current and power when temperature changes@1000 $\left[\mathrm{W} / \mathrm{m}^{2}\right]$

$$
i_{p v}=N_{p} i_{p h}-N_{s} i_{0}\left(e^{\frac{q}{N_{s} k A T_{c}}\left(i_{p v} R_{s}+v_{p v}\right)}-1\right)
$$

\section{CONTROL OF THE PHOtOVOlTAiC SYSTEM}

\section{A. Principle of the MPPT}

From equations (8) and (9) it can be seen that the currentvoltage and the power-voltage curves of a solar panel have dependency on the solar irradiance and the temperature of the solar cells. In Fig. 3, it can be seen that as the solar irradiance increases, so does the power delivered from the solar panel. The opposite occurs with the temperature of the solar cells, Fig. 4, which is inversely related to the power.

Considering the latter, it is necessary to use an MPPT strategy due to the presence of external disturbances, from the environment (temperature and solar irradiance), so in this way it ensures that the system is consistently delivering the maximum power available [11].

\section{B. Perturb and observe}

In order to have the PV system always delivering the maximum power available, a perturb and observe tracking strategy is proposed which is one of the most used in related literature [11]. In the Fig. 5, the flow chart of this technique is shown, which changes the voltage reference to which the PV panel is operating at every certain interval time (increase or decrease multiplied by $\Delta V$ ) and check whether this adjustement increases the power or not. Based on the measurements, it assigns a new reference so that the system always operates around the point of maximum power.

\section{Voltage control of the photovoltaic system}

In favor to follow the maximum power point, as seen in the previous section, it is necessary to perform a control of the voltage to establish the operating point of the solar array. Analysing the positive node of the capacitor in Fig. 1 by the $\mathrm{KCL}$, equation (10) is obtained,

$$
i_{p v}=i_{c}+i_{d c}
$$

Additionally, it is known that the behaviour of the capacitor's current is given by:

$$
i_{c}=C \frac{d v_{p v}}{d t}
$$

Combining equations (10) and (11) and multiplying them by $v_{p v}$, the subsequent is obtained:

$$
v_{p v} \frac{d v_{p v}}{d t}=\frac{v_{p v}}{C}\left(i_{p v}-i_{d c}\right)
$$

The power of the capacitor is given by:

$$
P_{c}=v_{p v}\left(i_{p v}-i_{d c}\right)
$$

Applying the chain differential rule in equation (12) and considering equation (13), it can be found that,

$$
\frac{d v_{p v}^{2}}{d t}=\frac{2 P_{c}}{C}
$$

Applying the Laplace transformation to the expression above, the transfer function of the capacitor in the $s$ plane is obtained as follows:

$$
\frac{v_{p v}^{2}}{P_{c}}=\frac{2}{s C}
$$

Once the transfer function is obtained, it is possible to design a closed-loop strategy using a Proportional-Integral (PI) controller as shown in Fig. 6. The transfer function associated to the PI controller is as follows:

$$
P I(s)=k_{p}+\frac{k_{i}}{s}
$$

The gain after the PI controller comes from a power balance given by equations (17) and (18). Note that the negative sign has to do with the fact that the capacitor is delivering power and not absorbing it, as was done in the development of the 


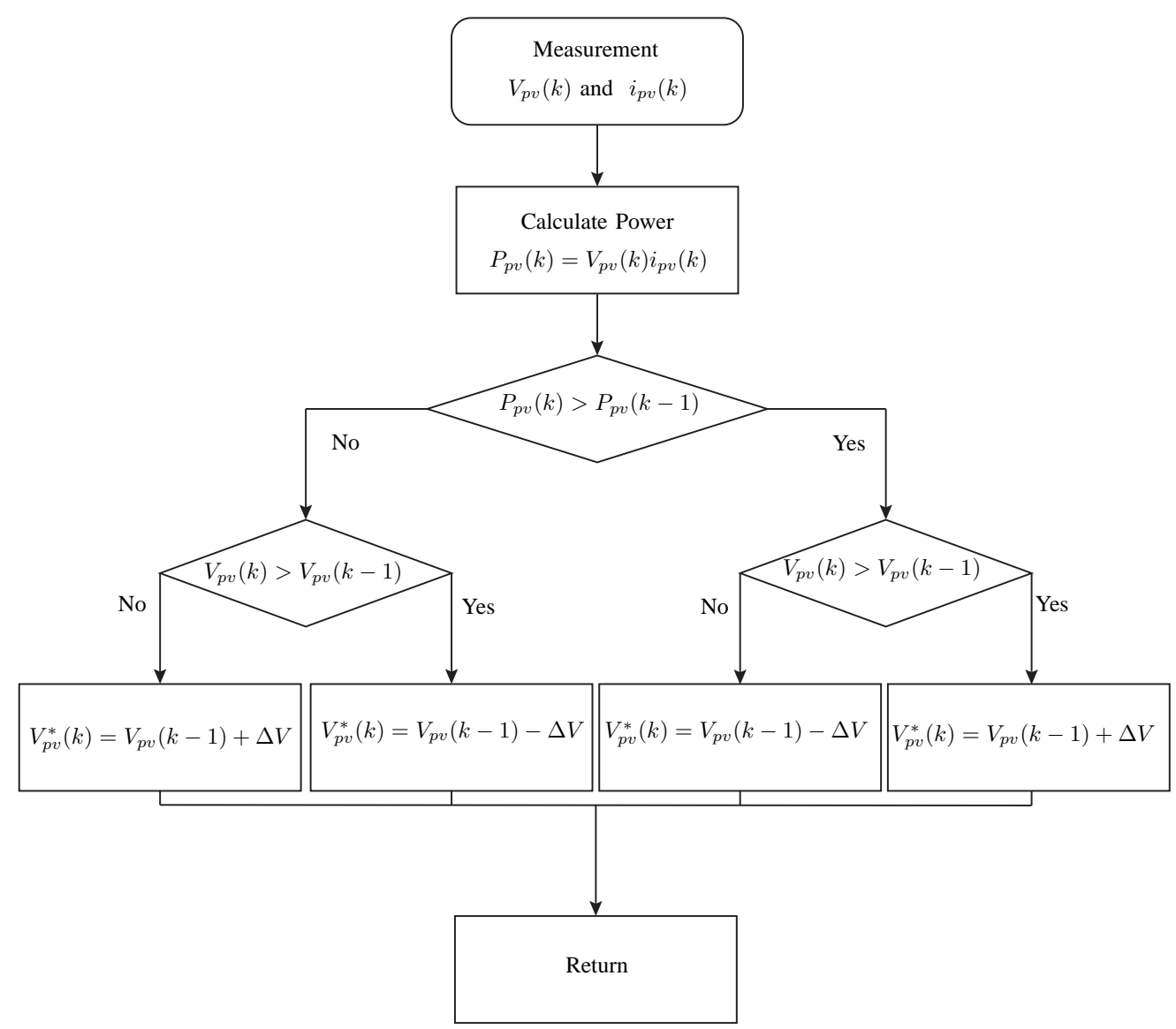

Fig. 5: Flow chart of the Perturb \& Observe algorithm

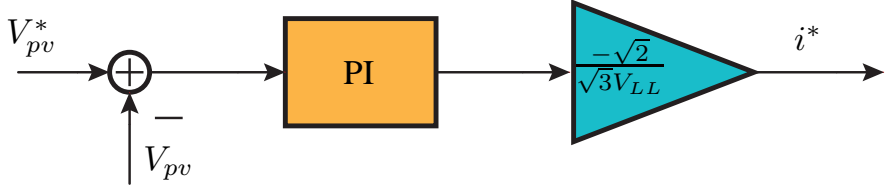

Fig. 6: Closed-loop strategy using a PI controller

transfer function. The value $\sqrt{2}$ is so that the current reference has its peak value.

$$
\begin{gathered}
P_{c}=P_{\text {grid }} \\
P_{c}=\sqrt{3} V_{L L} i
\end{gathered}
$$

\section{Predictive control}

To control the current introduced at the electrical system, a predictive control is used in [7], which is based on predicting the next state of the plant to be controlled through mathematical modelling. Using the KVL on the AC side of the converter of Fig. 1, equation (19) is obtained,

$$
\boldsymbol{v}=\boldsymbol{i} R+L \frac{d \boldsymbol{i}}{d t}+\boldsymbol{e}
$$

where $e$ is the grid voltage vector and $\boldsymbol{v}$ is the output voltage of the inverter.
The derivatives are implemented applying a forward Euler approximation as follows:

$$
\frac{d \boldsymbol{i}}{d t}=\frac{\boldsymbol{i}(k+1)-\boldsymbol{i}(k)}{T_{s}}
$$

Then, combining equations (19) and (20) and prior to mathematical simplifications, resulting in the following:

$$
\boldsymbol{i}(k+1)=\left(1-\frac{R T_{s}}{L}\right) \boldsymbol{i}(k)+\frac{T_{s}}{L}(\boldsymbol{v}-\boldsymbol{e})
$$

In Fig. 7 the proposed control scheme is shown. A Clarke transformation is performed to change the reference plane from $a b c$ to $\alpha \beta$ to the line currents, to reduce the computational burden required to solve equation (21). The voltage $v_{p v}$ is used in both the predictive control and in the $v_{p v}^{*}$ control. With the above, the reference currents and the predicted currents for the next sampling time are calculated. In the optimisation stage, all the possible currents in the next sampling time are evaluated, as function of the states in Table I, to determine thus, the switching state vector that will allow the closest output to $i^{*}(k+1)$.

Then, the implemented cost function is as follows:

$$
g(k+1)=\left|\boldsymbol{i}^{*}-\boldsymbol{i}(k+1)\right|
$$




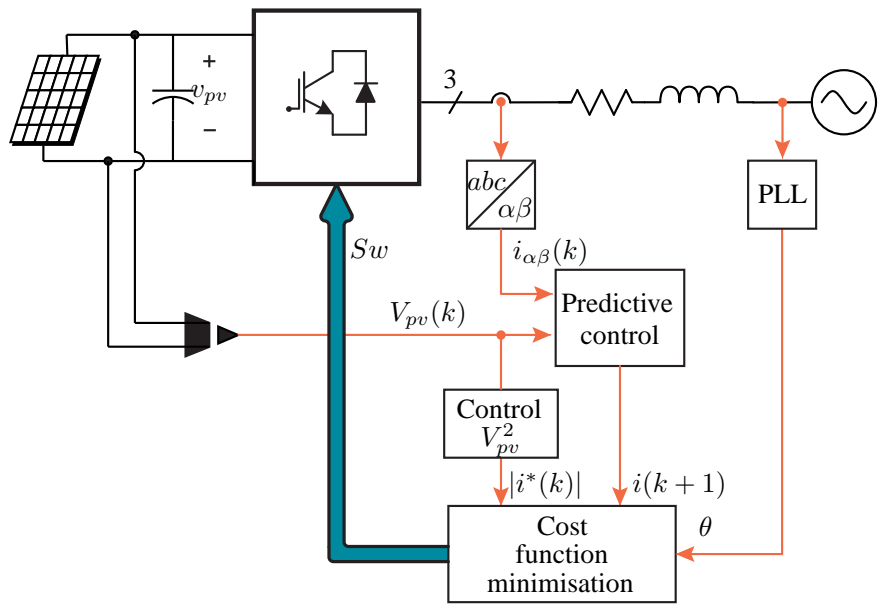

Fig. 7: Predictive control scheme

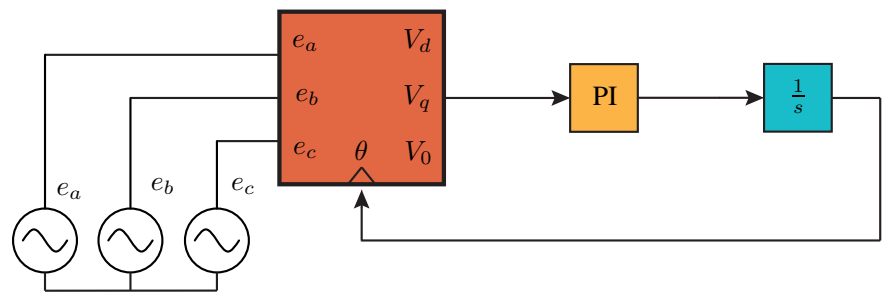

Fig. 8: Phase-locked loop $P L L$

Note that for solving equation (21), it is necessary to have the value of $e$. This value can be obtained from measurements or from estimations using the backward Euler approximation in equation (19), obtaining:

$$
\boldsymbol{e}(k-1)=\boldsymbol{v}(k-1)-\frac{L}{T_{s}} \boldsymbol{i}(k)-\left(R-\frac{L}{T_{s}}\right) \boldsymbol{i}(k-1)
$$

It is considered also that $\boldsymbol{e}(k) \approx \boldsymbol{e}(k-1)$.

\section{E. Phase-locked loop (PLL)}

To define the used reference current in the cost function minimisation, it is necessary to have the angle of the reference current. For this, a phase-locked loop $(P L L)$ is implemented (see Fig. 7) which synchronises the injected current and the grid voltage $(f p \approx 1)$. In Fig. 8 , the implemented $P L L$ is shown [12].

\section{RESULTS}

With the aim to confirming the proposed system, the proposal is implemented in Matlab\&Simulink and simulation tests are carried out. The results are obtained by confronting the model to irradiance and temperature perturbations of the solar cell, to evaluate the performance of the MPPT technique along with the control of the power injection to the grid. The used parameters are shown in Table III, whereas the implemented sampling frequency for the control is $10[k H z]\left(T_{s}=100[\mu s]\right)$. The operation conditions of the solar panel are an irradiance of $1,000\left[\mathrm{~W} / \mathrm{m}^{2}\right]$ and cell temperature of $25\left[{ }^{\circ} \mathrm{C}\right]$. Step changes are applied, and they consist in a $30 \%$ of the solar irradiance
TABLE III: Simulation parameters

\begin{tabular}{c|cc} 
Parameter & Value & Measurement \\
\hline \hline$R_{p}$ & 3035 & {$[\Omega]$} \\
$R_{s}$ & 0.1 & {$[\Omega]$} \\
$q$ & $1.6 \cdot 10^{-19}$ & {$[C]$} \\
$k$ & $1.3805 \cdot 10^{-23}$ & {$\left[\frac{J}{K}\right]$} \\
$A$ & 1.602 & \\
$T_{r e f}$ & 25 & {$\left[{ }^{\circ} \mathrm{C}\right]$} \\
$E_{g}$ & 1.1 & {$[e V]$} \\
$i_{s c}$ & 5.67 & {$[A]$} \\
$v_{o c}$ & 46.43 & {$[V]$} \\
$N_{p}$ & 1 & \\
$N_{s}$ & 7 & {$[m F]$} \\
$C$ & 10000 & {$\left[V_{r m s}\right]$} \\
$V_{L L}$ & 40 & \\
$k_{p}$ & 10 & {$[\Omega]$} \\
$k_{i}$ & 300 & {$[m H]$} \\
$R$ & 1 & \\
$L$ & 10 & \\
\hline \hline
\end{tabular}
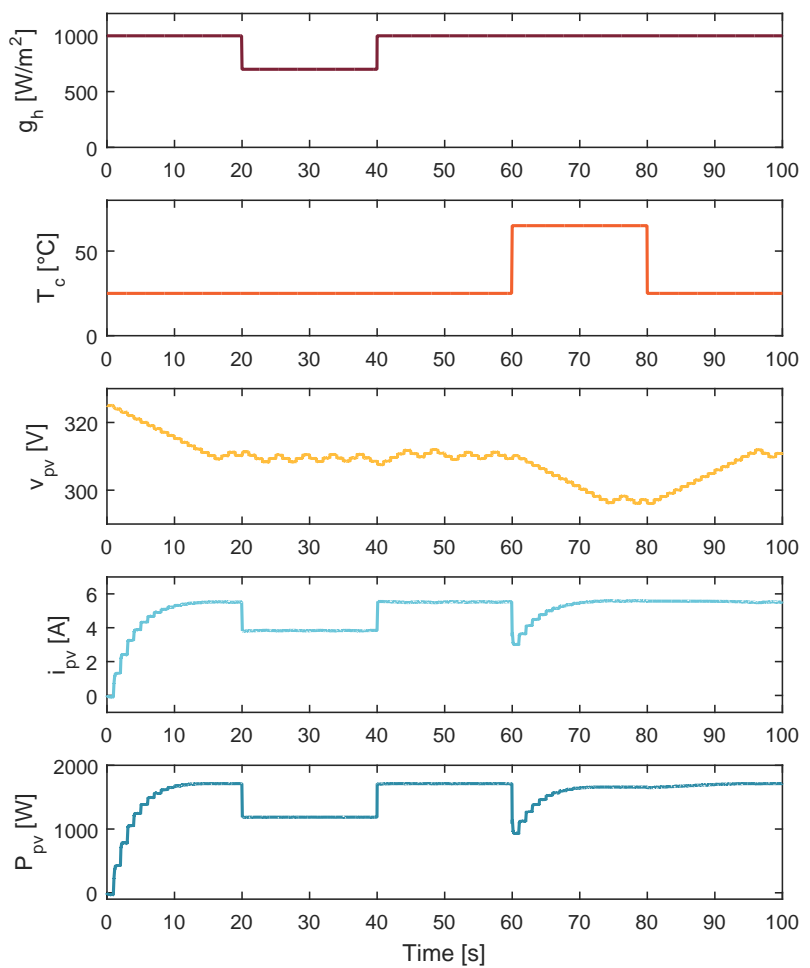

Fig. 9: Behaviour of the solar panel with solar irradiance and solar cells temperature changes

between 20 and $40[s]$ and an increase in the solar cell temperature of up to $40\left[{ }^{\circ} \mathrm{C}\right]$ during $20[s]$ from $\left.60[s]\right)$. The behaviour of the developed scheme is shown in Fig. 9. Is showed that the control of $v_{p v}$ is more critical under the solar cell temperature variation, imposing a reduction of $20[V]$, whereas the resulting current $i_{p v}$ allows that the obtained power (inferior sub-figure) can be the maximum power (affected proportionally by the changes of $g_{h}$ ).

The regulation of $P_{p v}$ also controls the injected current 

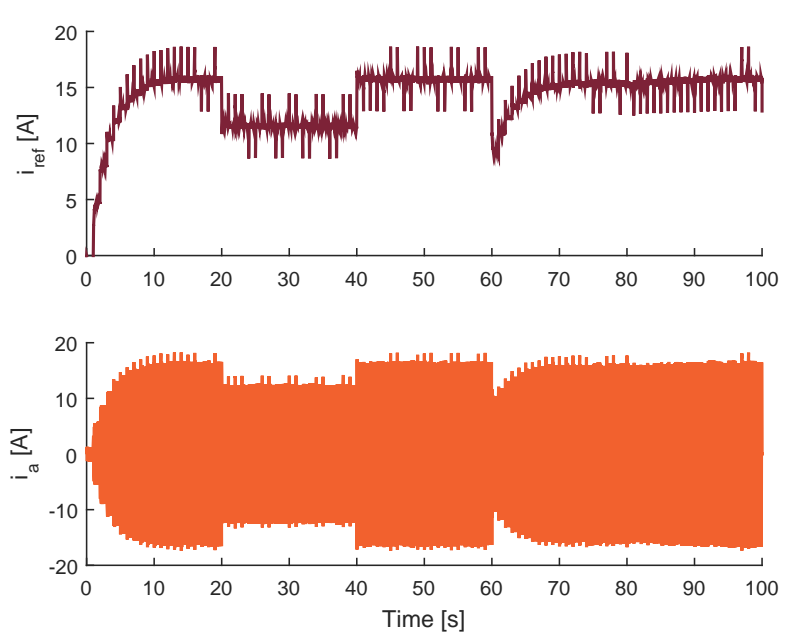

Fig. 10: Tracking of the reference current
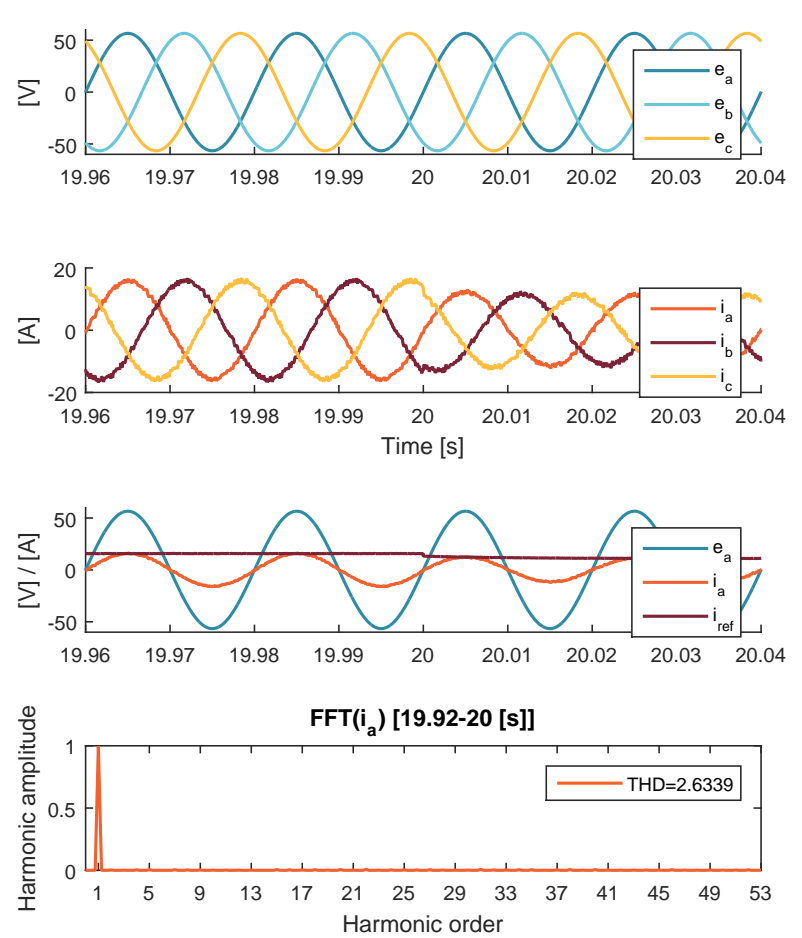

Fig. 11: Grid voltage, line current, PLL, reference current and FFT

into the grid to obtain the desired power flow. The magnitude reference of $i$ along with its response are indicated in Fig. 10. The response speed and the tracking of the current are proper and adequate. The quality of the injected power is verified analysing the results from Fig. 11 (capture of the AC side voltages and currents in the interval 19.46 a $20.04[s])$. The response in the time domain proves that the synchronisation between voltage and current is adequate, whereas in the frequency domain the quality and the accomplishment of the IEEE 519-1992 norm with a low THD of $2.63 \%$ is fulfilled.

\section{Conclusions}

This work presents a current predictive control of a singlestage two-level voltage source inverter coupled to a photovoltaic system. The control of the current works together with a Perturb \& Observe strategy in order to obtain the maximum power point tracking of the PV array. The presented results show a high quality of the injected current, allowing thus the maximum potential of the solar photovoltaic system. The MPPT has a swift response in front of disturbances coming from the environment (less than 5 [s] when there are changes in the solar irradiance that is shining over the PV array).

\section{ACKNOWLEDGEMENTS}

The authors thank the financial support of the FONDECYT Programme through the Regular 1160690 and the Postdoctoral 3170014

\section{REFERENCES}

[1] M. de Energa, "Energa 2050 poltica energtica de chile," Ministerio de Energa, 2016

[2] B. Mountain and P. Szuster, "Solar, solar everywhere: Opportunities and challenges for australia's rooftop pv systems," IEEE Power and Energy Magazine, vol. 13, no. 4, pp. 53-60, July 2015.

[3] R. Teodorescu, P. Liserre, and P. Rodríguez, Grid Converters for Photovoltaic and Wind Power Systems, 1st ed. Wiley - IEEE, 2011, p. 398.

[4] S. Hattori, F. Kurokawa, and K. Ueno, "Performance characteristics of single-stage AC-DC full-bridge converter," in 2015 9th International Conference on Power Electronics and ECCE Asia (ICPE-ECCE Asia). Seoul, South Korea: IEEE, 2015, pp. 1368-1373. [Online]. Available: https://ieeexplore.ieee.org/document/7167957/

[5] T.-F. Wu, C.-H. Chang, L.-C. Lin, and C.-L. Kuo, "Power Loss Comparison of Single- and Two-Stage Grid-Connected Photovoltaic Systems," IEEE Transactions on Energy Conversion, vol. 26, no. 2, pp. 707-715, 2011. [Online]. Available: http://ieeexplore.ieee.org/document/5751664/

[6] R. Kadri, J. P. Gaubert, and G. Champenois, "An Improved maximum power point tracking for photovoltaic grid-connected inverter based on voltage-oriented control," IEEE Transactions on Industrial Electronics, vol. 58, no. 1, pp. 66-75, 2011. [Online]. Available: https://ieeexplore.ieee.org/document/5595500/

[7] J. Rodríguez and P. Cortés, Predictive Control of Power Converters and Electrical Drives, 1st ed. Wiley - IEEE, 2012, p. 231.

[8] A. Fethi, B. Douadi, M. Laour, and B. El-madjid, "Power control of three phase single stage grid connected photovoltaic system," in 2016 International Renewable and Sustainable Energy Conference (IRSEC). Marrakech, Morocco: IEEE, 2016, pp. 1136-1141. [Online]. Available: http://ieeexplore.ieee.org/document/7983983/

[9] A. C. Sunny, B. Das, P. R. Kasari, A. Sarkar, S. Bhattacharya, and A. Chakrabarty, "SVPWM based decoupled control of active and reactive power for single stage grid connected solar PV system," in 2016 IEEE 7th Power India International Conference, PIICON 2016, no. 1. Bikaner, India: IEEE, 2017. [Online]. Available: https://ieeexplore.ieee.org/document/8077328/

[10] N. Pandiarajan and R. Muthu, "Mathematical modeling of photovoltaic module with simulink," in Electrical Energy Systems (ICEES), 2011 1st International Conference on. IEEE, 2011, pp. 258-263.

[11] L. Lu and P. Liu, "Research and simulation on photovoltaic power system maximum power control," in Electrical and Control Engineering (ICECE), 2011 International Conference on. IEEE, 2011, pp. 13941398.

[12] Z. Liu, J. Liu, and Y. Zhao, "A unified control strategy for threephase inverter in distributed generation," IEEE Transactions on Power Electronics, vol. 29, no. 3, pp. 1176-1191, March 2014. 